\title{
Low-Light Irradiation at the Beginning or the End of the Daily Dark Period Accelerates Leaf Expansion and Growth in Spinacia oleracea L.
}

\author{
Keiko Ohashi-KaneKo*, Masahide TaKase and Kenji Kurata \\ Department of Biological \& Environmental Engineering, Graduate School of Agricultural and Life Sciences, \\ University of Tokyo, Tokyo 113-8657, Japan
}

(Received November 22, 2010)

\begin{abstract}
Supplemental red light irradiation at the beginning of the dark period or blue light irradiation at the end of the dark period at a low level $(0.6 \%$ of the irradiance of the light period) compared to no supplemental irradiation (control) promoted biomass production and was accompanied by an increase in the leaf area in spinach. Photosynthetic rate and stomatal conductance measured under white light in the leaves of plants grown under supplemental lighting during the dark period were the same as those of the control plants. Microscopic analysis of the transverse and longitudinal directions of the leaves revealed that red light irradiation at the beginning of the dark period increased leaf cell size, while leaf cell size was not affected by blue light irradiation at the end of the dark period. These results suggest that red light irradiation at the beginning of the dark period accelerates leaf expansion by an increase in leaf cell size and blue light irradiation at the end of the dark period accelerates leaf expansion by an increase in leaf cell number. The increase in leaf area by supplemental lighting leads to an increase in photosynthesis at the whole-plant level, which contributes to the enhancement of biomass production under suboptimal light irradiation.
\end{abstract}

Keywords : blue light, light emitting diode, red light, spinach, supplemental lighting

\section{INTRODUCTION}

Cultivation using artificial lighting in an environmentally controlled room enables stable vegetable production regardless of the weather conditions. For management of controlled-environment agricultural facilities, it is necessary to save electrical energy costs. Therefore, it is desirable to achieve high productivity or high vegetable quality even under limited light intensity. Application of supplemental lighting to crops grown under artificial lighting during the night is a practical and reasonable measure for promoting their growth, because the electricity rate at night is generally lower than in the daytime in Japan. In previous studies concerning supplemental greenhouse lighting, extended lighting with supplemental light promoted the growth of not only sweet peppers (when the photoperiod was extended from 20 to $24 \mathrm{~h}$ ) grown under low irradiation at a northern latitude in winter (Demers et al., 1998; Demers and Gosselin, 1999; Gosselin et al., 2001) but also the growth of lettuce and tsukena (supplemental lighting period from 23:00 to 07:00) grown under optimal irradiation at mid-latitudes in spring or fall (Fukuda et al., 2002). Since light-grown plant

\footnotetext{
*Current address: Biosystems \& Biofunctions Research Center, Research Institute, Tamagawa University, Tokyo 194-8610, Japan

Corresponding author: Keiko Ohashi-Kaneko, fax : +81-42-739-7221, e-mail : ohashik@lab.tamagawa.ac.jp
} 


\section{K. OHASHI-KANEKO ET AL.}

seedlings irradiated with far red light for a short period at the end of the day commonly show marked enhancement of growth (Smith et al., 1991), some scientists have tried to study the effect of a short period of supplemental lighting during the dark period on plant growth. Interestingly, Sung et al. (1998) reported that growth of cucumber seedlings was promoted by exposure to low blue-enriched light for $5 \mathrm{~min}$ during the twilight period. They explained that this promotion of growth was caused by an increase in photosynthesis along with an increase in stomatal conductance during the daytime. Hanyu and Shoji (2002) observed that red light irradiation at the beginning of the dark period for $30 \mathrm{~min}$ or blue light irradiation at the end of the dark period for $30 \mathrm{~min}$ at a low level (17\% of the light intensity of the light period) increased the dry matter by $20 \%$ in spinach. The other two combinations of light quality and lighting hour, however, did not promote growth. This indicates that red or blue light photoreceptors participate in these light-quality and timedependent events. These low-energy responses of plants will contribute to the establishment of lighting technology to achieve high productivity while saving electrical energy costs in cultivation using artificial lighting. However, the mechanism underlying the promotion of biomass by low supplemental irradiation during the dark period has not yet been clarified. Both red light and blue light affect many events in photomorphogenesis besides photosynthesis (for reviews, see Smith et al., 1991; Briggs and Huala, 1999; Christie and Briggs, 2001). For example, plants grown under red light alone or blue light deficient conditions have thinner and wider leaves (Britz and Sager, 1990). Schuerger et al. (1997) reported that the amount of blue light present in the light source is correlated with the thickness of the leaf mesophyll tissues, which is accompanied by an increased leaf thickness in pepper plants. These changes in leaf expansion should affect photosynthetic efficiency at the whole-plant level. Therefore, whether changes in morphological characteristics, including leaf development, contribute to the enhancement of biomass production by low supplemental irradiation during the dark period should be investigated.

In the present study, we investigated how low supplemental irradiation at the beginning or end of the dark period affected the photosynthetic characteristics and the morphological and anatomical features of leaves. These analyses should provide clues to clarify the mechanism underlying the promotion of biomass production by supplemental lighting during the dark period. Spinach was used as the plant material because leafy vegetables including spinach can be grown without disease under low light irradiation in cultivation using artificial lighting in an environmentally controlled room.

\section{MATERIALS AND METHODS}

\section{Plant culture}

Spinach (Spinacia oleracea L. cv. Try) was used as the plant material. Seeds were germinated in plastic containers $(415 \times 230 \times 93 \mathrm{~mm})$ filled with vermiculite irrigated by tap water. Seedlings were grown for 8 days in an environmentally controlled room (the culture area of the room was $28 \mathrm{~m}^{2}$ ) with a 12 -h light period and light/dark temperature of $25 \pm 1 / 20 \pm 1{ }^{\circ} \mathrm{C}$. Irradiance was provided by four fluorescent lamps (FPL55EX-N; Iwasaki Electric Co., Tokyo, Japan) and maintained at a photosynthetic photon flux density (PPFD) of $150 \mu \mathrm{mol} \mathrm{m}^{-2} \mathrm{~s}^{-1}$ at the top of plants during the light period. At 8 days after germination, one seedling was transplanted to each of 18 plastic bottles $(500 \mathrm{~mL})$ containing an aerated nutrient solution and was grown hydroponically in environmentally controlled growth chambers (the culture area of the chamber was $0.25 \mathrm{~m}^{2}$ ). The chamber was operated with a 12-h light period, light/dark temperature of $23 \pm 1 / 18 \pm 1^{\circ} \mathrm{C}$ and a PPFD of 220 $\mu \mathrm{mol} \mathrm{m} \mathrm{m}^{-2} \mathrm{~s}^{-1}$ at the top of plants during the light period. From 14 days after germination, plants were grown under supplemental lighting treatments, i.e., the plants were irradiated with red light or blue light for $30 \mathrm{~min}$ at the beginning, middle or end of the dark period (Fig. 1). Red light or blue light was supplied by four LED boards. One LED board comprised a transparent acrylic board 
(a) Dusk

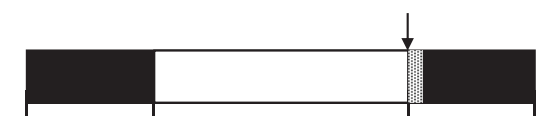

(b) Midnight

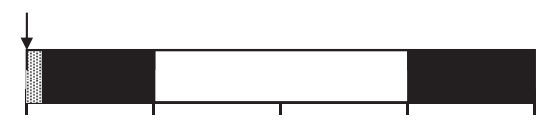

(c) Dawn

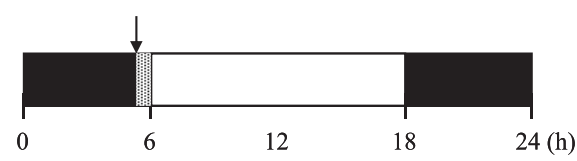

Fig. 1 Time schedule of supplemental red or blue light irradiation at the end (dusk; a), middle (midnight; b) and beginning (dawn; c) of the dark period. The light period was 06:00-18:00 and the night period 00:00-06:00 and 18:00-24:00. Arrows indicate the start of supplemental red or blue light irradiation.

$(50 \times 570 \mathrm{~mm})$ with 87 red (L645-03V; Epitex Inc., Kyoto, Japan) or 87 blue (L470-03V; Epitex Inc., Kyoto, Japan) LEDs installed. Four boards of each color were equally spaced and set up below white fluorescent lamps and above the plants inside a growth chamber (Fig. 2). The spectral photon distributions of each LED board and fluorescent lamp measured with a spectrometer (HR2000CG-UV-NIR; Ocean Optics Inc., Florida, USA) are shown in Fig. 3. The photon flux density (PFD) of supplemental red or blue light was $30 \mu \mathrm{mol} \mathrm{m}^{-2} \mathrm{~s}^{-1}$ at the top of the plants. The position of the fluorescent lamps was adjusted so that the PPFD of light that passed the LED board was $220 \mu \mathrm{mol} \mathrm{m}^{-2} \mathrm{~s}^{-1}$ at the top of the plants during the light period. Plants grown without supplemental irradiation were used as controls. A total of 54 plants were subjected to each set of light treatment conditions. Plants were supplied with a nutrient solution described by Ohashi-Kaneko et al. (2007), with pH maintained at 6.0 to 6.5 . The nutrient solution was renewed once every 5 days and was continuously aerated. The strength of the nutrient solution was varied depending on plant growth as follows (days after germination): $2 / 5$ at 8 days, and $4 / 5$ from 13 days. Experiment was repeated three times. Through the three experiments, growth analysis, leaf structural observation and gas exchange measurements were separately performed. In the second and third experiments, the supplemental lighting treatment at the middle of the dark period was omitted.

Plant growth analysis

The length and width of the second and third leaves were measured every 2 days between 14 and 42 days after germination. Swart et al. (2004) reported that the product of leaf length multiplied by leaf width correlated with leaf area. In a preliminary experiment, we confirmed that plotting the leaf area against the product of leaf length multiplied by leaf width gave the same

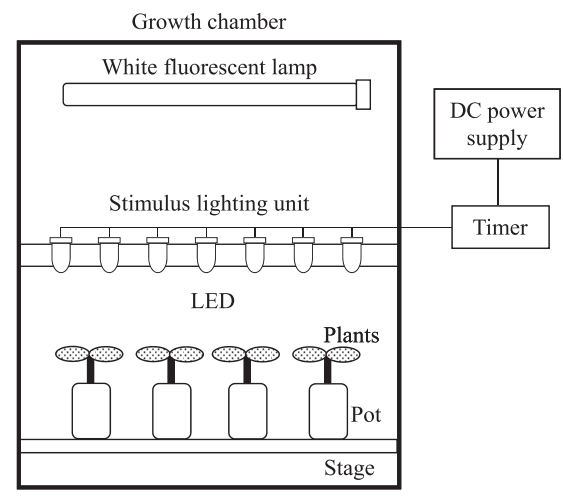

Fig. 2 A schematic diagram of the growth apparatus used, equipped with a stimulus lighting unit. 


\section{K. OHASHI-KANEKO ET AL.}

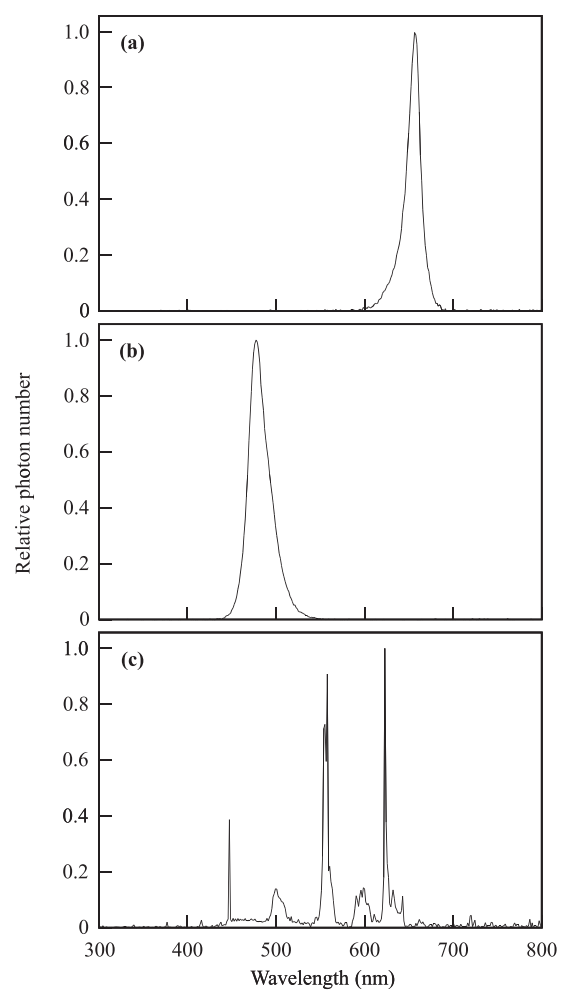

Fig. 3 Relative spectral photon flux distribution of red light (a), blue light (b) and white light (c). Red light or blue light was provided from a red or blue LED and white light was provided from a white fluorescent lamp. The number of photons was counted at intervals of $1 \mathrm{~nm}$.

regression line for the second or third leaves of spinach plants regardless of the supplemental lighting treatment, including the control (data not shown). The linear regression line obtained was used to determine the leaf area of the second or third leaves every 2 days from 14 days after germination. Six plants per treatment were harvested at 42 days after germination in the middle of the day. Leaf area was measured, and leaf blade, stems including petioles, and roots were separately oven-dried at $65^{\circ} \mathrm{C}$ for 3 days.

\section{Leaf structural observations}

Leaf structural observations were carried out on the second and third leaves of three 38-dayold plants in each supplemental lighting treatment. Leaf segments $(1.5 \times 3 \mathrm{~mm})$, avoiding major veins, were taken from the tip, middle and basal part of the leaf blade with a razor blade. The segments were fixed overnight at $4^{\circ} \mathrm{C}$ with a solution containing $2.5 \%(\mathrm{v} / \mathrm{v})$ glutaraldehyde and 84 $\mathrm{mM}$ phosphate buffer ( $\mathrm{pH}$ 7.2) with continuous degassing. According to the methods of Tsukaya et al. (1993) the fixed segments were dehydrated with ethanol and embedded in resin (Technovit 7100; Kulzer \& Co., GmbH, Wehrheim, Germany).

Light microscopy (CK2; Olympus, Tokyo, Japan) was carried out with 4- $\mu$ m thick transverse sections of the leaves sliced with a rotary microtome (PR-50; Yamato Kohki Industrial, Saitama, Japan) and stained with $1 \%$ toluidine blue. Light micrographs taken with a CCD camera were stored in a personal computer through video capture. The length or width of each cell was calculated using image analysis software (GIMP; http://www.gimp.org/index.html).

Gas exchange measurement

Gas exchange was measured on young, fully expanded leaves of 42- to 45-day-old plants with 
a portable gas-exchange system (LI-6400; Li-Cor Inc., Lincoln, NE, USA). Light was provided from a 35-W white halogen lamp (JR12V35WKW/3GZ4; Phoenix Electric Co., Hyogo, Japan), and PPFD was adjusted by shading with cloth. Measurements were made at a leaf temperature of 23 ${ }^{\circ} \mathrm{C}$, an ambient $\mathrm{CO}_{2}$ partial pressure $(p \mathrm{Ca})$ of $36 \mathrm{~Pa}$, and a leaf-to-air vapor pressure difference of 1.0 to $1.2 \mathrm{kPa}$.

Determination of chlorophyll (Chl) and ribulose-1,5-bisphosphate carboxylase/oxygenase (Rubisco)

Determination of Chl and Rubisco was carried out on young, fully expanded leaves of 42- to 45-day-old plants according to the methods of Makino et al. (1994). The leaf blade was homogenized in $50 \mathrm{mmol} \mathrm{L}^{-1}$ sodium phosphate buffer ( $\mathrm{pH} 7.0$ ) containing $2 \mathrm{mmol} \mathrm{L}^{-1}$ iodoacetic acid, $0.8 \%(\mathrm{v} / \mathrm{v}) 2$-mercaptoethanol and $5 \%(\mathrm{v} / \mathrm{v})$ glycerol. The total Chl was measured using part of this homogenate. To solubilize membrane-bound Rubisco, Triton X-100 was added to a final concentration of $0.1 \%(\mathrm{v} / \mathrm{v})$ to a portion of this homogenate (Makino and Osmond, 1991). After centrifugation, the amount of Rubisco in the supernatant was measured spectrophotometrically after formamide extraction of Coomassie Brilliant Blue R-250-stained subunit bands separated by sodium dodecyl sulfate-polyacrylamide gel electrophoresis. A calibration curve was obtained using Rubisco purified from tomato leaves.

\section{RESULTS}

\section{Plant growth}

The effect of supplemental lighting at the beginning of the dark period on plant growth is shown in Fig. 4 (a) and 4 (b). Total plant dry weight and leaf area of the spinach plants grown under red light irradiation at the beginning of the dark period were 69 and $64 \%$ greater than those of the plants grown under no supplemental light irradiation (control plants), while there was no significant difference between the spinach plants grown under blue light irradiation and control plants.

Supplemental red or blue light irradiation in the middle of the dark period did not affect plant growth significantly (Fig. 4 (c), 4 (d)).

When spinach plants were irradiated with supplemental lighting at the end of the dark period, total plant dry weight and leaf area increased by 24 and $42 \%$ under supplemental blue light treatment conditions; whereas, they were not affected under red light treatment conditions (Fig. 4 (e), 4 (f)).

\section{Leaf area, leaf length and leaf width of single leaves}

Observed changes in the leaf area of second or third leaves after transfer to supplemental lighting treatments are shown in Fig. 5. Leaf area of both the second leaves and third leaves of the spinach plants grown under red light irradiation at the beginning of the dark period was significantly greater than that of the plants grown under control conditions after 26 days (Fig. 5 (a), 5 (b)). The leaf area did not differ between the spinach plants grown under blue light irradiation and control plants.

Supplemental red or blue light irradiation in the middle of the dark period did not affect leaf area of the second or third leaves basically, although the leaf area of the third leaves of the plants grown under red light irradiation was slightly greater than that of the plants grown under control conditions at 32 and 34 days after germination (Fig. 5 (c), 5 (d)).

When spinach plants were irradiated with supplemental lighting at the end of the dark period, the leaf area of only the third leaves in the plants grown under blue light irradiation was greater than that of the control plants after 34 days, whereas the area of the second leaves was not affected significantly by blue light irradiation (Fig. 5 (e), 5 (f)). Supplemental red light irradiation at the end of the dark period did not affect leaf area of either the second or third leaves.

There were no significant differences in the ratio of leaf length to leaf width at final harvest, 

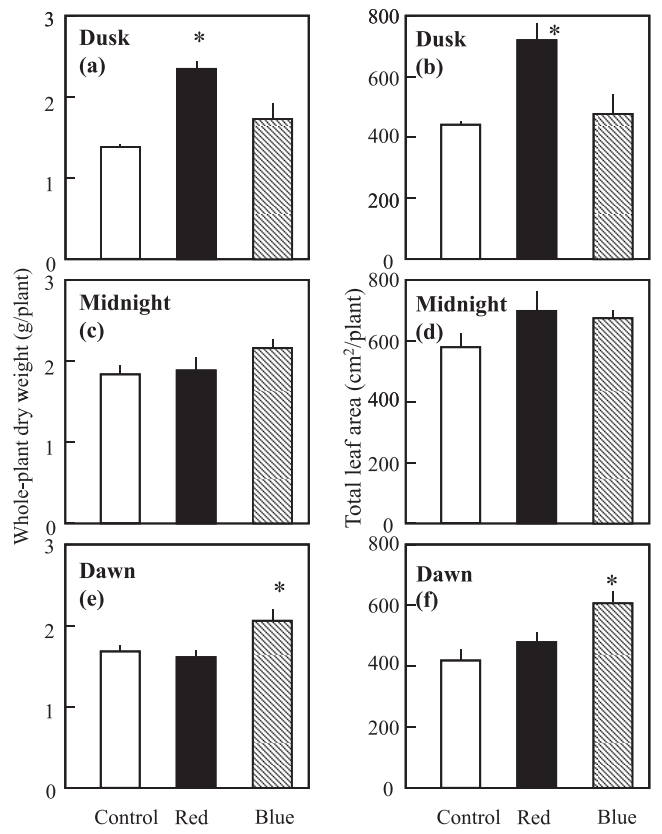

Fig. 4 Whole-plant dry weight and total leaf area of spinach plants at 42 days after germination. Plants were grown hydroponically under supplemental red light (closed bars), blue light (hatched bars) or no supplemental (open bars; control) irradiation at the end (dusk; a, b), middle (midnight; c, d) or beginning (dawn; e,f) of the dark period for 28 days. Vertical bars indicate the standard error $(n=6)$. Means with an asterisk $(*)$ were significantly different at the $5 \%$ level by pairwise $t$-tests comparing control and light irradiation treatments.

irrespective of the light quality or the timing of supplemental irradiation, although the ratio was greater for the third leaves of the plants irradiated with red light at the beginning of the dark period than for control plants (Table 1).

\section{Leaf anatomy}

Light micrographs of transverse sections of the tip, middle and basal parts of the second or third leaf blades irradiated with supplemental red light at the beginning of the dark period or with supplemental blue light at the end of the dark period, which both cause an increase in biomass production and leaf area, are shown in Fig. 6. Light micrographs of longitudinal sections were also examined (data not shown). Width (transverse direction of the leaf) and length (longitudinal direction of the leaf) of adaxial epidermal and palisade cells were measured from the light micrographs (Fig. 7). In the plants grown under supplemental red light irradiation at the beginning of the dark period, the length and width of adaxial epidermal cells (Fig. 7 (a), 7 (c)) and palisade cells (Fig. 7 (e), 7 (g)) from the second leaf blades were larger than those of the plants grown under control conditions, although there were no significant differences in the adaxial epidermal cell length of middle and tip parts and adaxial epidermal cell width of middle part and palisade cell width of middle part. Length and width of adaxial epidermal cells (Fig. 7 (b), 7 (d)) and palisade cells (Fig. 7 (f), 7 (h)) of the middle and tip of third leaf blades were significantly larger than those of the plants grown under control conditions. Supplemental blue light irradiation at the end of the dark period treatment tended to decrease length and width of adaxial epidermal cells (Fig. 7 (b), 7 (d)) and palisade cells (Fig. 7 (f), 7 (h)) of the third leaves relative to controls. These results suggested that supplemental red light irradiation at the beginning of the dark period accelerates leaf expansion by an increase in leaf cell size, and supplemental blue light irradiation at the end of the dark period 


\section{GROWTH PROMOTION BY SUPPLEMENTAL LIGHTING DURING DARK PERIOD}
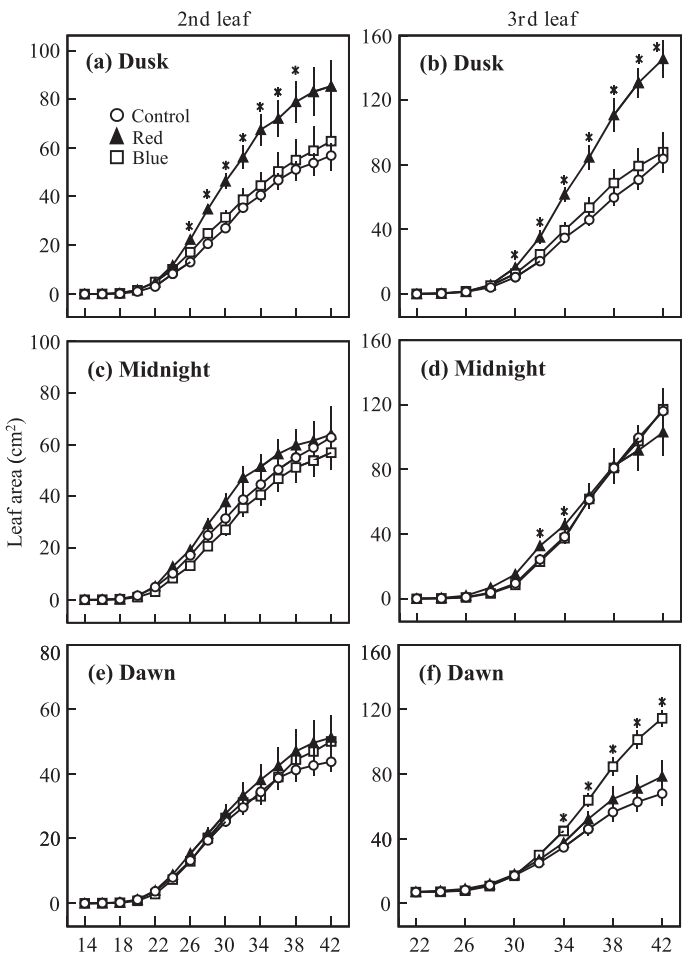

Days after germination

Fig. 5 Changes in leaf area of the second (a, c, e) and third (b, d, f) leaves of spinach plants after transfer to supplemental light irradiation treatments. Plants were grown hydroponically under supplemental red light (closed triangles), blue light (open squares) or no supplemental (open circles; control) irradiation at the end (dusk; a, b), middle (midnight; c, d) or beginning (dawn; e, f) of the dark period for 28 days. Vertical bars indicate the standard error $(n=6)$. Means with an asterisk $(*)$ were significantly different at the $5 \%$ level by pairwise $t$-tests comparing control and light irradiation treatments each day.

Table 1 Length/width ratio (leaf index) of second or third leaves of spinach plants at 42 days after germination.

\begin{tabular}{llcc}
\hline & & \multicolumn{2}{c}{ Leaf index } \\
\cline { 3 - 4 } & & 2nd leaf & 3rd leaf \\
\hline \multirow{2}{*}{ Dusk } & $\mathrm{R}$ & $1.86 \pm 0.13$ & $1.77 \pm 0.03^{*}$ \\
& $\mathrm{~B}$ & $1.95 \pm 0.15$ & $1.80 \pm 0.15$ \\
& Control & $2.18 \pm 0.10$ & $2.09 \pm 0.07$ \\
& $\mathrm{R}$ & $2.04 \pm 0.12$ & $1.70 \pm 0.12$ \\
& $\mathrm{~B}$ & $2.18 \pm 0.11$ & $1.76 \pm 0.10$ \\
& Control & $2.08 \pm 0.06$ & $1.74 \pm 0.09$ \\
& $\mathrm{R}$ & $2.25 \pm 0.11$ & $2.11 \pm 0.11$ \\
& $\mathrm{~B}$ & $2.11 \pm 0.06$ & $1.72 \pm 0.12$ \\
& Control & $2.20 \pm 0.12$ & $1.95 \pm 0.09$ \\
\hline
\end{tabular}

Plants were grown hydroponically under supplemental red light (R), blue light (B) or no supplemental (control) irradiation at the end (dusk) or the beginning (dawn) of the dark period for 28 days. Values are means \pm standard errors $(n=6)$. Means with an asterisk $(*)$ were significantly different at the $5 \%$ level by pairwise $t$-test comparing control and light irradiation treatments. 

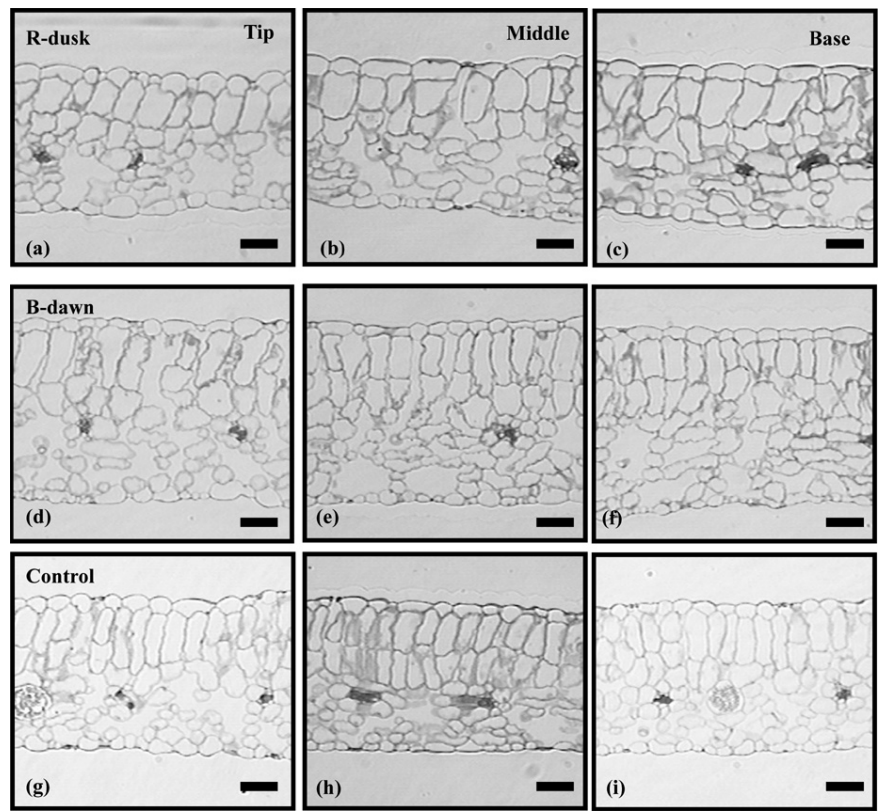

A
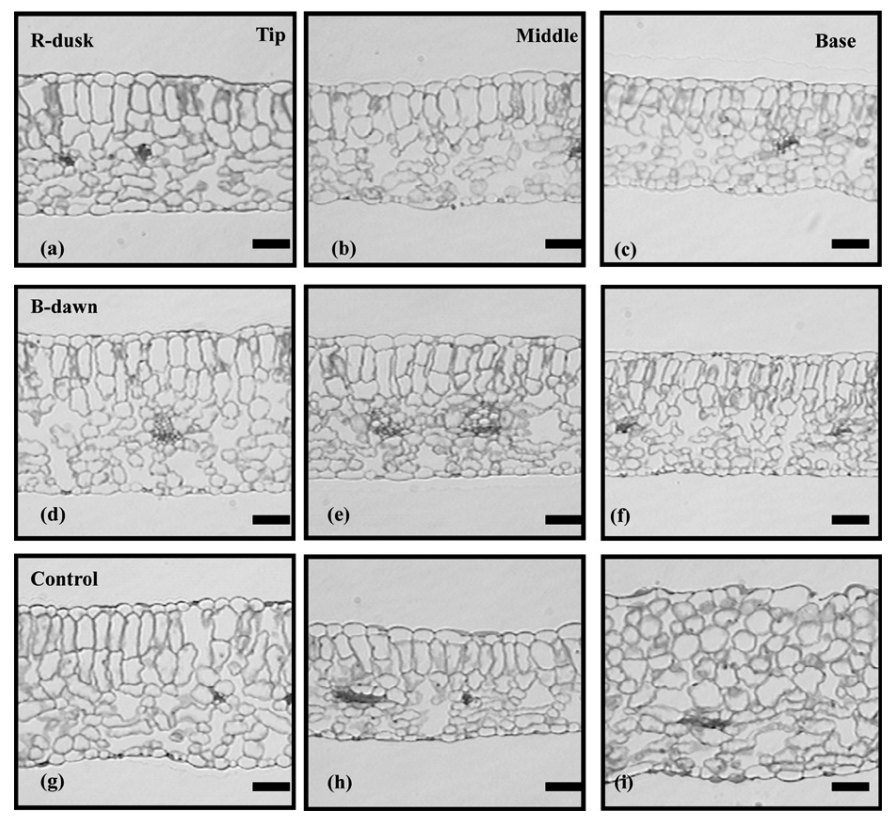

B

Fig. 6 Light micrographs of transverse sections of the tip (a, d, g), middle (b, e, h) and basal (c, f, i) regions of the second (A) and third (B) leaf blades of spinach plants at 38 days after germination. The plants were irradiated with red light at the beginning of (R-dusk; a, b, c), blue light at the end of (B-dawn; $\mathrm{d}, \mathrm{e}, \mathrm{h}$ ), or no supplemental light (Control; g, h, i) during the dark period for 24 days. Bars $=50 \mu \mathrm{m}$. 


\section{GROWTH PROMOTION BY SUPPLEMENTAL LIGHTING DURING DARK PERIOD}
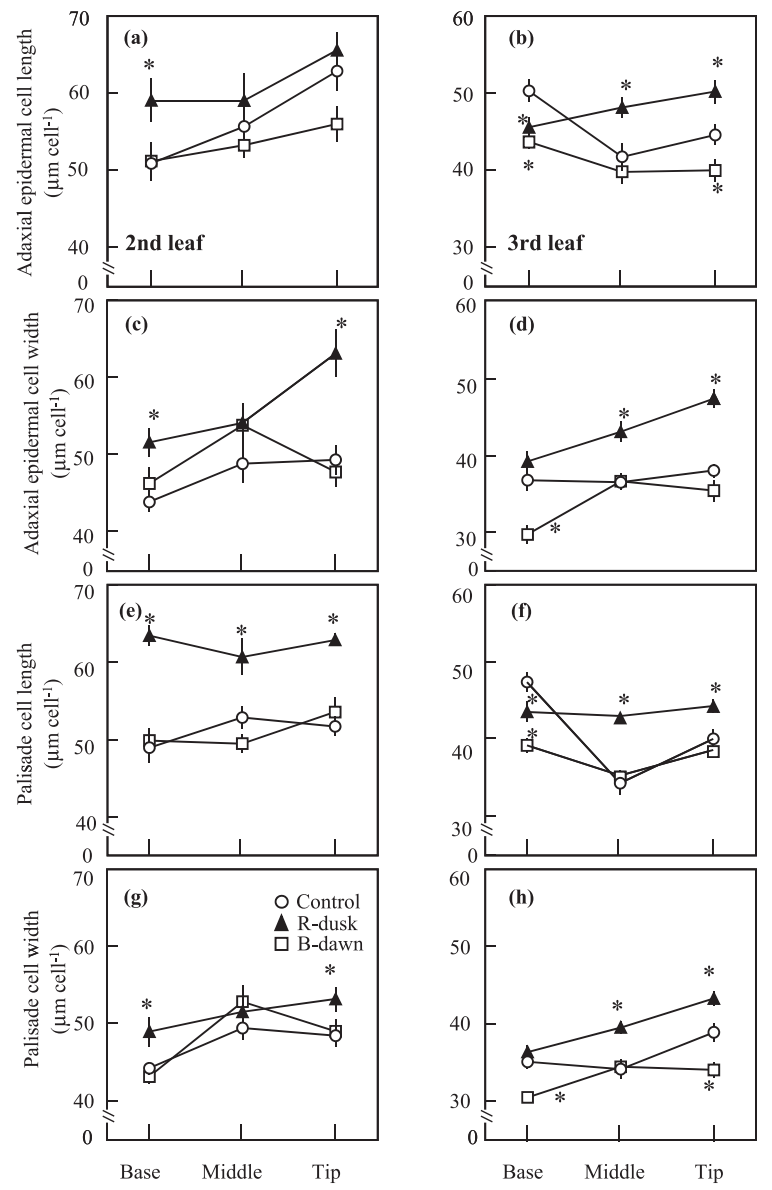

Fig. 7 Length (a, b) and width (c, d) of adaxial epidermal cells and length (e, f) and width (g, h) of palisade tissue cells of second (a, c, e, g) or third (b, d, f, h) leaf blades of spinach plants at 38 days after germination. The plants were irradiated with red light at the beginning of (R-dusk; closed triangles), blue light at the end of (B-dawn; open squares) or no supplemental light (Control; open circles) during the dark period for 24 days. Vertical bars represent standard errors $(n=3)$. Means with an asterisk $(*)$ were significantly different at the $5 \%$ level by pairwise $t$-tests comparing control and light irradiation treatments.

accelerates leaf expansion by an increase in leaf cell number.

Photosynthetic parameters and contents of Rubisco and Chl

Although stomatal conductance in the leaves of the spinach plants grown under supplemental red light irradiation at the beginning of the dark period were significantly greater than those of the plants grown under control conditions, this increased conductance did not contribute to an increase in photosynthetic rate (Table 2). Supplemental blue light irradiation at the beginning and supplemental red or blue light irradiation at the end of the dark period did not affect photosynthetic rate, stomatal conductance or transpiration rate.

There were no significant differences in the contents of Rubisco and Chl among the supplemental lighting treatments (Table 2). These results suggest that the enhancement of biomass production by supplemental red light irradiation at the beginning or blue light irradiation at the end of the dark period is explained not by an increase in photosynthesis but rather by an enlargement of leaf area. 


\section{K. OHASHI-KANEKO ET AL.}

Table 2 Photosynthetic rate, stomatal conductance and transpiration rate at $p \mathrm{Ca}=36 \mathrm{~Pa}$, and the contents of Rubisco and Chl of the young, fully expanded leaves of 42- to 45-day old plants.

\begin{tabular}{clccccc}
\hline Treatment & $\begin{array}{c}\text { Photosynthetic } \\
\text { rate }(\mu \mathrm{mol} \\
\left.\mathrm{CO}_{2} \mathrm{~m}^{-2} \mathrm{~s}^{-1}\right)\end{array}$ & $\begin{array}{c}\text { Stomatal } \\
\text { conductance } \\
\left(\mathrm{mol} \mathrm{H}_{2} \mathrm{O} \mathrm{m}^{-2} \mathrm{~s}^{-1}\right)\end{array}$ & $\begin{array}{c}\text { Transpiration rate } \\
\left(\mathrm{mol} \mathrm{H}_{2} \mathrm{O} \mathrm{m}^{-2} \mathrm{~s}^{-1}\right)\end{array}$ & $\begin{array}{c}\text { Rubisco } \\
\left(\mathrm{g} \mathrm{m}^{-2}\right)\end{array}$ & $\begin{array}{c}\text { Chl } \\
\left(\mathrm{mg} \mathrm{m}^{-2}\right)\end{array}$ \\
\hline \multirow{2}{*}{ Dusk } & $\mathrm{R}$ & $9.69 \pm 0.11$ & $1.210 \pm 0.173^{*}$ & $4.23 \pm 0.65^{*}$ & $1.24 \pm 0.09$ & $463 \pm 25(2.47)$ \\
& $\mathrm{B}$ & $10.79 \pm 0.28$ & $0.492 \pm 0.087$ & $3.06 \pm 0.57$ & $1.60 \pm 0.12$ & $570 \pm 26(2.53)$ \\
& Control & $10.99 \pm 0.94$ & $0.588 \pm 0.090$ & $3.20 \pm 0.86$ & $1.58 \pm 0.11$ & $538 \pm 30(2.42)$ \\
Dawn & $\mathrm{R}$ & $9.39 \pm 0.28$ & $0.781 \pm 0.122$ & $3.01 \pm 0.39$ & $1.64 \pm 0.17$ & $493 \pm 40(3.11)$ \\
& $\mathrm{B}$ & $9.56 \pm 0.30$ & $0.772 \pm 0.127$ & $2.83 \pm 0.19$ & $1.58 \pm 0.11$ & $563 \pm 43(3.16)$ \\
& Control & $8.79 \pm 0.56$ & $0.785 \pm 0.100$ & $2.61 \pm 0.17$ & $1.48 \pm 0.14$ & $460 \pm 61(3.14)$ \\
\hline
\end{tabular}

Measurements were made at a leaf temperature of $23^{\circ} \mathrm{C}$ and a leaf-to-air vapor pressure difference of $1.1 \pm 0.1$ $\mathrm{kPa}$. Plants were grown hydroponically under supplemental red light (R), blue light (B) or no supplemental (control) irradiation at the end (dusk) or the beginning (dawn) of the dark period for 31 days. Values are means \pm standard errors $(n=6)$. Means with an asterisk $(*)$ were significantly different at the $5 \%$ level by pairwise $t$-test comparing control and light irradiation treatments.

\section{DISCUSSION}

The promotion of growth of spinach plants by supplemental red or blue light irradiation at the beginning or end of the dark period was accordant with the results reported by Hanyu and Shoji (2002). This increased biomass was not caused by an increase in the photosynthesis per unit leaf area during the light period (Table 2). Sung et al. (1998) reported that a brief exposure to blue light at the end of the dark period caused an acceleration of growth in cucumber. They also observed that photosynthetic rates measured under white light were higher along with an increase in stomatal conductance in leaves irradiated with supplemental blue light at the end of the dark period compared to no supplemental light. This increase in photosynthetic rate by increased stomatal conductance is probably one of the major causes of the acceleration of growth of cucumber plants. However, this stimulation of stomatal opening cannot be explained solely by the generally known stimulation of stomatal opening by blue light irradiation (Sharkey and Raschke, 1981; Karlsson, 1986), because photosynthetic rate and stomatal conductance were measured under white light (Sung et al., 1998). Therefore, it should be analyzed whether a brief exposure to blue light at the end of the dark period promotes stomatal opening during the light period in leaves of several plant species. There may be variation with plant species.

In the present study, the irradiance of supplemental lighting during the dark period was only $0.6 \%$ of the total irradiance of the light period throughout the cultivation period. Furthermore, the growth promotion by supplemental lighting during the dark period was obviously dependent on a combination of light quality and the timing of the supplemental lighting. Therefore, the photosynthesis during supplemental lighting seems not to be a cause of the growth promotion. The relationship between the net photosynthetic rate of the spinach leaves grown under white fluorescent lamps versus light intensity is shown in Fig. 8. In this curve, the light compensation point (a light intensity at which the net photosynthetic rate is maintained at zero) is estimated to be between 40 and $50 \mu \mathrm{mol} \mathrm{m} \mathrm{m}^{-2} \mathrm{~s}^{-1}$. The light intensity of supplemental lighting in this study $\left(30 \mu \mathrm{mol} \mathrm{m}^{-2} \mathrm{~s}^{-1}\right)$ is near the light compensation point (Fig. 8). It is not possible that photosynthesis during supplemental lighting led to the increase in biomass of $20 \%$ or more compared to no supplemental lighting plants.

In the plants supplemented with red light irradiation at the beginning or blue light irradiation at the end of the dark period, the total leaf area increased, with an increase in dry weight of the plants (Fig. 4). We speculated that supplemental lighting during the dark period stimulated the expansion of the leaves directly, which resulted in an increase in both photosynthesis at the whole- 
GROWTH PROMOTION BY SUPPLEMENTAL LIGHTING DURING DARK PERIOD

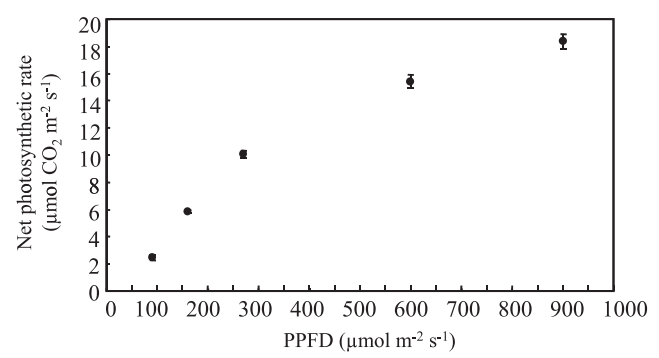

Fig. 8 Net photosynthetic rate at $p \mathrm{Ca}=36 \mathrm{~Pa}$ as a function of light intensity. Light was provided by a white halogen lamp. Measurements were made at a leaf temperature of $23^{\circ} \mathrm{C}$ and a leaf-to-air vapor pressure difference of $1.1 \pm 0.1 \mathrm{kPa}$ between 42 and 45 days after germination. Plants were grown hydroponically under no supplemental irradiation.

plant level and biomass production. Van Volkenburgh (1999) reported that variation in leaf size has been attributed to differences in cell number, or cell size, or a combination of the two. Interestingly, microscopic analysis of the leaves in the present study suggested that red light irradiation at the beginning of the dark period accelerated leaf expansion by an increase in leaf cell size (cell elongation) and blue light irradiation at the end of the dark period accelerated leaf expansion by an increase in leaf cell number (Fig. 7).

When light irradiation stimulates expansion of dicotyledonous leaves, it is observed that proton excretion from leaf cells is induced simultaneously (Van Volkenburgh and Cleland, 1990). It is thought that a proton pump in the plasma membrane carries out this activity (Linnemeyer et al., 1990). A decrease in apoplastic pH loosens the cell wall (Rayle and Cleland, 1992), which is related to cell elongation. On the other hand, cells expand by accumulating solutes, absorbing water, generating turgor pressure, and extending the cell wall, which are associated with the proton pump (Van Volkenburgh, 1999). Thus, the proton pump plays an important role in the dilation of the cell. Both red and blue light can stimulate the proton pump by separate mechanisms (Van Volkenburgh, 1999) although the effective light intensity of red or blue light for driving the proton pump was not mentioned. Therefore, it is possible that a brief low red light irradiation expands the cell directly, independent of the photosynthetic activity, which promotes the growth of the leaf. However, it is unknown why only red light irradiation at the beginning of the dark period causes the cell expansion and blue light irradiation at the end of the dark period does not. In addition, it is unknown whether the cell expands depending on both timing of the supplemental lighting and light quality.

Polar cell expansion in the leaf-width direction is regulated by the $A N$ gene and the polar cell expansion in the leaf-length direction is regulated by the ROT-3 gene; the two genes act independently (for review, see Tsukaya, 2002). The ratio of leaf length to leaf width was not changed by supplemental red or blue light irradiation at the beginning or end of the dark period. Supplemental lighting during the dark period dose not seem to affect the expression of both genes.

It is well known that cell division in plants is correlated with carbohydrate supply, and leaves starved for photosynthate or other nutrients will develop fewer cells than those grown under optimal conditions (for review, see Van Volkenburgh, 1999). However, the relationship between the mechanisms for maintaining cell division and regulation of leaf expansion rate is unclear (Van Volkenburgh, 1999). Moreover, there is no report that irradiation of blue light promotes cell division in plants. Therefore, we will next examine the effect of supplemental blue light irradiation at the end of the dark period on the relationship between the mechanisms for maintaining cell division, especially the regulation of cell cycle in spinach leaves, and the expansion of the leaves.

To elucidate the mechanism underlying the promotion of biomass productivity and leaf expansion by supplemental lighting during the dark period, the photoreceptor related to this reaction 


\section{K. OHASHI-KANEKO ET AL.}

should be identified. Hanyu and Shoji (2004) observed that when plants were irradiated with supplemental red and far-red light sequentially at the beginning of the dark period, acceleration of growth by red light was cancelled by far-red light. This suggests that phytochrome acts on a mechanism related to cell expansion and the promotion of leaf growth by red light irradiation at the beginning of the dark period. The analysis of leaf development using the techniques of molecular genetics should be performed. For example, we will next observe the development, cell division and cell elongation in various mutants deficient in photoreceptors such as phytochrome, cryptochrome and phototropin.

In the present study, we were able to obtain new information showing that supplemental red light irradiation at the beginning of the dark period accelerated leaf expansion by an increase in leaf cell size and supplemental blue light irradiation at the end of the dark period accelerated leaf expansion by an increase in leaf cell number. This increase in the leaf area led to the promotion of photosynthesis at the whole-plant level and biomass production of spinach plants grown under suboptimal irradiation. The results obtained in the present study are useful in establishing effective lighting technology to achieve high productivity in cultivation using artificial lighting.

\section{REFERENCES}

Briggs, W. R., Huala, E. 1999. Blue-light photoreceptors in higher plants. Annu. Rev. Cell Dev. Biol. 15: $33-62$.

Britz, S. J., Sager, J. C. 1990. Photomorphogenesis and photoassimilation in soybean and sorghum grown under broad spectrum or blue-deficient light source. Plant Physiol. 94: 448-454.

Christie, J. M., Briggs, W. R. 2001. Blue light sensing in higher plants. J. Biol. Chem. 276: 11457-11460.

Demers, D. A., Gosselin, A. 1999. Supplemental lighting of greenhouse vegetables: Limitations and problems related to long photoperiods. Acta Hort. 481: 469-473.

Demers, D. A., Gosselin, A., Wien, H. C. 1998. Effects of supplemental light duration on greenhouse sweet pepper plants and fruit yields. J. Am. Soc. Hort. Sci. 123: 202-207.

Fukuda, N., Nishimura, S., Fumiki, Y. 2002. Effect of supplemental lighting during the period from middle of night to morning on photosynthesis and leaf thickness of lettuce (Lactuca sativa L.) and tsukena (Brassica campestris L.). Acta Hort. 633: 237-244.

Gosselin, A., Ayari, O., Erhioui, M. B., Papadopoulos, A., Dorais, M. 2001. Optimization of HPS supplemental lighting for greenhouse tomato. Acta Hort. 548: 343-347.

Hanyu, H., Shoji, K. 2002. Acceleration of growth in spinach by short-term exposure to red and blue light at the beginning and at the end of the daily dark period. Acta Hort. 580: 145-150.

Hanyu, H., Shoji, K. 2004. Growth responses of several kinds of vegetables to brief exposures to supplemental lights during the night. (Japanese text with English abstract) Abiko Research Laboratory Report, Central Research Institute of Electric Power Industry, No. U03053. 20 pp.

Karlsson, P. E. 1986. Blue light regulation of stomata in wheat seedlings. I. Influence of red background illumination and initial conductance level. Physiol. Plant. 66: 202-206.

Linnemeyer, P. A., Van Volkenburgh, E., Cleland, R. E. 1990. Characterization and effect of light on the plasma membrane $\mathrm{H}^{+}$-ATPase of bean leaves. Plant Physiol. 94: 1671-1676.

Makino, A., Nakano, H., Mae, T. 1994. Responses of ribulose-1,5-bisphosphate carboxylase, cytochrome $f$, and sucrose synthesis enzymes in rice leaves to leaf nitrogen and their relationships to photosynthesis. Plant Physiol. 105: 173-179.

Makino, A., Osmond, B. 1991. Effects of nitrogen nutrition on nitrogen partitioning between chloroplasts and mitochondria in pea and wheat. Plant Physiol. 96: 355-362.

Ohashi-Kaneko, K., Takase, M., Kon, N., Fujiwara, K., Kurata, K. 2007. Effect of light quality on growth and vegetable quality in leaf lettuce, spinach and komatsuna. Environ. Control Biol. 45: 189-198.

Rayle, D. L., Cleland, R. E. 1992. The acid growth theory of auxin-induced cell elongation is alive and well. Plant Physiol. 99: 1271-1274.

Schuerger, A. C., Brown, C., Stryjewski, E. C. 1997. Anatomical features of pepper plants (Capsicum annuит L.) grown under red light-emitting diodes supplemented with blue or far-red light. Ann. Bot. 79: 273-282. 


\section{GROWTH PROMOTION BY SUPPLEMENTAL LIGHTING DURING DARK PERIOD}

Sharkey, T. D., Raschke, K. 1981. Effect of light quality on stomatal opening in leaves of Xanthium strumarium L. Plant Physiol. 68: 1170-1174.

Smith, H., Whitelam, G. C., McCormac, A. C. 1991. Do the members of the phyochrome family have different roles? Physiological evidence from wild-type, mutant and transgenic plants. In "Phytochrome Properties and Biological Action", Springer-Verlag, Berlin, p 217-236.

Sung, I. K., Kiyota, M., Hirano, T. 1998. The effects of time and intensity of supplemental blue lighting during morning twilight on growth and physiological performance of cucumber seedlings. Life Support Biosphere Sci. 5: 137-142.

Swart, E. A. M. D., Groenwold, R., Kanne, H. J., Stam, P., Marcelis, L. F. M., Voorrips, R. E. $2004 . \quad$ Nondestructive estimation of leaf area for different plant ages and accessions of Capsicum annuum L. J. Hort. Sci. Biotech. 79: 764-770.

Tsukaya, H. 2002. Leaf Development. The Arabidopsis Book, American Society of Plant Biologists, USA. p $1-23$.

Tsukaya, H., Naito, S., Rédei, G. P., Komeda, Y. 1993. A new class of mutations in Arabidopsis thaliana, acaulis1, affecting the development of both influorescences and leaves. Development 118: 751-764.

Van Volkenburgh, E. 1999. Leaf expansion - an integrating plant behaviour. Plant Cell Environ. 22: 14631473.

Van Volkenburgh, E., Cleland, R. E. 1990. Light-stimulated cell expansion in bean (Phaseolus vulgaris L.) leaves. I. Growth can occur without photosynthesis. Planta 182: 72-76. 